\title{
SACRAL (S3) SEGMENTAL NERVE STIMULATION AS A TREATMENT FOR URGE INCONTINENCE IN PATIENTS WITH DETRUSOR INSTABILITY: RESULTS OF CHRONIC ELECTRICAL STIMULATION USING AN IMPLANTABLE NEURAL PROSTHESIS
}

\author{
J. L. H. R. BOSCH AND JAN GROEN \\ From the Department of Urology, Erasmus University and Academic Hospital, Rotterdam, The Netherlands
}

\section{ABSTRACT}

Purpose: We studied the effects of sacral (S3) nerve stimulation in patients with urge incontinence due to detrusor instability.

Materials and Methods: A permanent S3 foramen electrode was implanted in 18 patients (average age 46 years) who had shown a good response during temporary stimulation via a percutaneously placed wire electrode. Average followup was 29 months.

Results: The average voiding frequency and pad use per 24 hours decreased significantly. Improvement in several urodynamic parameters was noted. The correlation between symptomatic and urodynamic improvement was incomplete.

Conclusions: Neuromodulation appears to be a valuable treatment option in these patients.

KEY WORDS: urinary incontinence; urination disorders; nerves; bladder, neurogenic; sacrococcygeal region

Most patients with urge incontinence and idiopathic detrusor instability are initially treated conservatively with bladder retraining, pelvic floor exercises and biofeedback, while in the majority this regimen will be supplemented with anticholinergic drugs. The urinary incontinence guideline panel has summarized the literature on results achieved with various drugs for urge incontinence, and found that oxybutynin and terodiline appeared to be the most effective. ${ }^{1}$ Subjective cure rates of up to $44 \%$ over placebo and decreased urinary incontinence rates in up to $56 \%$ over placebo were achieved with these drugs. ${ }^{1}$ Interestingly, no changes in urodynamic parameters were found in well designed drug trials despite symptomatic improvement. ${ }^{2,3}$ Fortunately, many patients seem to be satisfied with a less than optimal result. Patients who do not achieve an acceptable condition remain a therapeutic problem and alternative procedures, with variable success rates, such as bladder transection, transvesical phenol injection of the pelvic plexus, augmentation ileocystoplasty and even urinary diversion, are being advocated. ${ }^{4}$

Unilateral sacral segmental nerve stimulation by a permanent foramen S3 electrode (neuromodulation) offers a nondestructive alternative for those whose condition is refractory to conservative measures. The aim of this treatment modality is to achieve detrusor inhibition by chronic electrical stimulation of afferent somatic sacral nerve fibers via an implanted electrode coupled to a subcutaneously placed pulse generator. The ratio of this treatment modality is based on the existence of spinal inhibitory systems that are capable of interrupting a detrusor contraction. Inhibition can be achieved by electrical stimulation of afferent anorectal branches of the pelvic nerve, afferent sensory fibers in the pudendal nerve and muscle afferents from the limbs. ${ }^{5-7}$ Most of these branches and fibers reach the spinal cord via the dorsal roots of the sacral nerves. Of the sacral nerve roots the S3 root is the most practical for use in chronic electrical stimulation. ${ }^{8}$ We evaluate the effectiveness of this treatment modality in patients with urge incontinence due to bladder instability.

Accepted for publication January 6, 1995

\section{MATERIALS AND METHODS}

Six men and 25 women (mean age 46 years) underwent a percutaneous test stimulation of the S3 sacral roots. ${ }^{8}$ Such a stimulation test is currently the only method available to evaluate whether this treatment option will work in an individual patient. Patients were selected on the basis of 3 criteria: 1) urge incontinence in combination with urodynamically demonstrated detrusor instability refractory to drug treatment (instability may be idiopathic or neurogenic), 2) a bladder capacity of at least $150 \mathrm{ml}$. but less than $500 \mathrm{ml}$. and 3) no untreated urinary tract infection, stone disease, diabetes mellitus, psychiatric disturbances, pregnancy or cerebrovascular accident less than 6 months previously, as well as no anatomical abnormalities, infection or decubitus at the future operative site.

The initial and baseline diagnostic evaluation included a history and physical examination, urinalysis, urine cytology studies, plain abdominal $x$-ray, ultrasound of the kidneys, cystoscopy, 2, 4-day voiding-incontinence diaries (registering pad use, frequency of leaks, voided volume and voiding frequency) and a video urodynamic examination that included a free flow rate determination, filling cystometry at a rate of 80 $\mathrm{ml}$. per minute and pressure-flow electromyographic studies. Filling cystometry studies were performed with the subject in the most provocative position, that is standing. The methods, units and definitions in relation to the urodynamic studies conformed to the standards recommended by the International Continence Society. ${ }^{9}$

Percutaneous test stimulation. This procedure consists of acute test stimulation followed by a sub-chronic test phase. In acute test stimulation a spinal needle, insulated by an angiographic catheter sheath, is placed percutaneously in the left and right S3 foramina and electrically stimulated by an external neuro-stimulator. The muscle response, which typically is a levator ani contraction and flexion of the great toe when S3 is stimulated, is used as a biological marker for correct needle placement. Apart from the stimulation of efferent ( $\alpha$-motor) fibers, which induce the muscle responses, afferent somatic nerve fibers are stimulated to inhibit the micturition reflex. The side with the best muscle response is 
chosen for placement of the test electrode. Good muscle reaponses on 1 or both sides were found in all patients.

In the sub-chronic test phase a 3 -zero steel guide wire is used as a temporary electrode and placed in the left or right S3 foramen. The guide wire is introduced into the foramen through the angiographic catheter sheath after removal of the spinal needle. Subsequently, the guide wire is continuously stimulated with a nerve stimulator for 3 to 5 days. The stimulation parameters used were pulse width $210 \mu \mathrm{sec}$, frequency 10 pulses per second and amplitude 0.5 to $20 \mathrm{~mA}$. The patient again kept a voiding-incontinence diary during this period. If there was greater than a $50 \%$ decrease in the number of leakage episodes and/or pads used the test was deemed successful and the patient was offered permanent implantation. Tests were successful in 19 of 31 patients (61\%). Because 1 woman refused surgery 18 patients $(58 \%)$ subsequently underwent permanent implantation.

Implantation. The complete device consisted of a foramen electrode connected to a subcutaneously placed pulse generator via a lead extension (fig. 1). The initial pulse generator was implanted in the first 8 patients and an improved generator was implanted in the remainder. The implant procedure was described in detail by Siegel. ${ }^{10}$ The initial stimulation parameters after activation of the pulse generator were pulse width $210 \mu$ sec., frequency 10 or 15 pulses per second and mean amplitude $2.7 \pm 0.4$ volts (standard error).

Followup studies included voiding-incontinence diaries at $1,3,6,9,12,15,18$ and 24 months, and a complete urodynamic examination 6 months after permanent implantation. The Mann-Whitney $U$ test was used to compare patient data before and after permanent implantation. The level of statistical significance was set at $p<0.05$.

\section{RESULTS}

The characteristics of the patients undergoing implantation are summarized in table 1. These patients had long histories of incontinence and on average had undergone more than 1 operation for the problem. Average followup was 29 months (13 patients were followed for 2 years or longer).

The symptomatic results are summarized in table 2 . Significant improvements in voiding frequency, average voided volume, number of incontinence episodes and number of pads used were found. The results at last followup are comparable

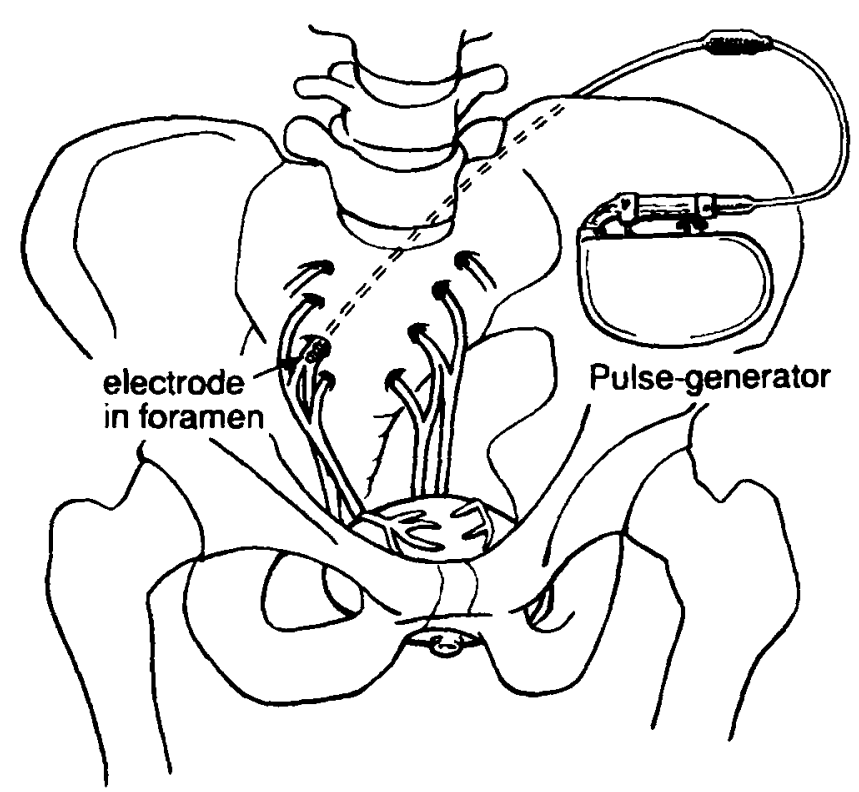

FIG. 1. Position of pulse generator, extension lead and S3 foramen electrode in patient with permanently implanted neural prosthesis.
TABLE 1. Characteristics of 15 women and 3 men undergoing implantation

\begin{tabular}{lcc}
\hline & Mean (range) \\
\hline Age (yrs.) & 46 & $(25-65)$ \\
No. previous operations for incontinence: & & \\
Bladder dilations excluded & 1.1 & $(0-2)$ \\
Bladder dilations included & 1.9 & $(0-6)$ \\
Yrs. previous drug use for incontinence & 3.8 & $(1-11)$ \\
Yrs. pad use & 7.5 & $(1-28)$ \\
Mos. followup & 29 & $(7-47)$ \\
\hline * Of 15 women 10 underwent hysterectomy in addition to the operations for
\end{tabular}
incontinence.

TABLE 2. Effect of neuromodulation on voiding-incontinence diary variables for the comparison of data at baseline and at last followup in 18 patients

\begin{tabular}{|c|c|c|c|c|c|}
\hline & \multicolumn{3}{|c|}{ Mean \pm SEM } & \multirow{2}{*}{$\begin{array}{l}\text { Mean } \\
\text { Change }\end{array}$} & \multirow{2}{*}{$\stackrel{p}{\text { palue }}$} \\
\hline & $\begin{array}{l}\text { Baseline } \\
\text { Value }\end{array}$ & $\begin{array}{l}\text { Test } \\
\text { Peniod }\end{array}$ & Followup & & \\
\hline $\begin{array}{l}\text { No. voiding epi- } \\
\text { sodes/24 hrs. }\end{array}$ & $15.3 \pm 1.5$ & $8.8 \pm 0.8$ & $9.4 \pm 0.6$ & -5.9 & 0.0005 \\
\hline $\begin{array}{l}\text { Av. voided vol. (ml.) } \\
\text { No. incontinence } \\
\text { episodes } / 24 \text { hrs. }\end{array}$ & $\begin{aligned} 127 & \pm 13 \\
7.5 & \pm 0.8\end{aligned}$ & $\begin{aligned} 179 & \pm 15 \\
1.3 & \pm 0.3\end{aligned}$ & $\begin{aligned} 178 & \pm 18 \\
1.9 & \pm 0.7\end{aligned}$ & $\begin{array}{l}+51 \\
-5.6\end{array}$ & $\begin{array}{l}0.006 \\
0.0002\end{array}$ \\
\hline No. pads $/ 24$ hrs. & $6.4 \pm 0.8$ & $1.6 \pm 0.3$ & $1.6 \pm 0.6$ & -4.8 & 0.0003 \\
\hline
\end{tabular}

to those achieved during the sub-chronic test phase, which indicates that there is no deterioration in response to stimulation with time. Partial (a 50 to $90 \%$ decrease in pad use and/or incontinence episodes) and excellent (greater than a $90 \%$ decrease) results were noted in 4 and 11 patients, respectively (table 3 ). Therefore, 15 of 18 patients ( $83 \%$ ) were treated successfully. Some patients continue to use 1 or 2 pads per 24 hours despite the fact that they report no incontinence episodes. Alternatively, some patients reported several episodes of slight leakage but they use only 1 pad per 24 hours. At last followup 9 of the 18 patients were reported to be completely dry (that is no leaks). Of the 13 patients followed for longer than 2 years 6 were reportedly completely dry at the last followup visit. The average pretreatment pad use in patients who were completely dry at the last followup visit was 5.8 per 24 hours compared to 7.7 among those who still reported occasional leakage. However, even in the latter group the pad use decreased from 7.7 to 3.9 per 24 hours. The evolution of pad use in the 13 patients followed for longer than 2 years is shown in figure 2.

The influence of neuromodulation on urodynamic variables is summarized in table 4 , which shows results of filling cystometry studies performed with the patient in the most provocative position, that is standing. At 6 months statistically significant changes were noted, consisting of an increase in bladder volume at normal desire from $204 \pm 34$ to $318 \pm 38$ $\mathrm{ml}$. and a decrease in amplitude of the maximum unstable contraction from $40 \pm 7$ to $30 \pm 9 \mathrm{~cm}$. water. More importantly, unstable contractions were no longer detectable in 8 patients at 6 months, while in the other 10 the average bladder volume at initial and maximum unstable contrac-

TABLE 3. Results of neuromodulation according to predefined criteria in 18 patients

\begin{tabular}{|c|c|c|c|}
\hline & \multicolumn{3}{|c|}{ No. Pts. } \\
\hline & $\begin{array}{l}\text { More Than } \\
\mathbf{9 0 \%} \text { Decrease } \\
\text { (excellent) }\end{array}$ & $\begin{array}{l}50 \text { to } 90 \% \\
\text { Decrease } \\
\text { (partial) }\end{array}$ & $\begin{array}{l}\text { Less Than } \\
\text { 50\% Decrease } \\
\text { (failed) }\end{array}$ \\
\hline Pad use & 11 & 3 & 4 \\
\hline Incontinence episodes & 10 & 5 & 3 \\
\hline $\begin{array}{l}\text { Pad use and/or inconti- } \\
\text { nence episodes }\end{array}$ & 11 & 4 & 3 \\
\hline
\end{tabular}




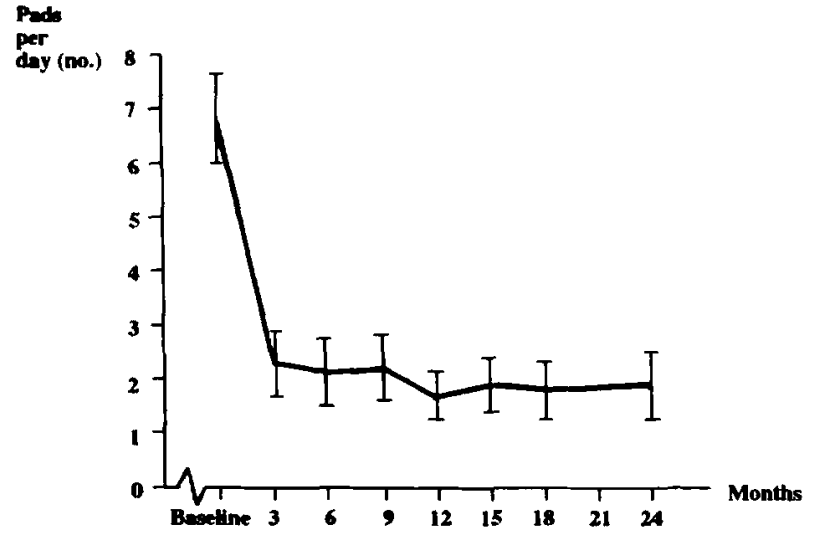

Fig. 2. Mean pad use per 24 hours in 13 patients after 2 years. Error bars indicate standard error of mean.

tions increased. However, statistical significance was not achieved in this subgroup.

There was an incomplete correlation between symptomatic and urodynamic changes. Of the 9 patients who were completely dry at last followup 3 still had urodynamic evidence of bladder instability, while 2 of 9 who were not dry at last followup had a stable bladder. An example of the baseline urodynamic study compared to the post-implant filling cystometry study with electrical stimulation turned on in 1 of the patients is shown in figure 3 .

Complications were mild. In 1 patient the electrode had to be repositioned twice because of dislocation, while later the extension lead had to be exchanged because of a lead fracture. In 2 patients repositioning of the lead was necessary because of dislocation (1) and faulty placement in the foramen during the original implantation (1). One patient com plained of pain at the side of the pulse generator, which resolved after repositioning the pulse generator away from the scar of a previous median laparotomy incision.

\section{DISCUSSION}

Neuromodulation has been advocated as a treatment option for various lower urinary tract dysfunctions, including incontinence, urge-frequency syndromes, pain syndromes, post-prostatectomy incontinence and urinary retention.11.12 Beneficial effects in patients with clinical conditions other than urge incontinence due to detrusor instability have been established in an empirical fashion, ${ }^{13}$ and still lack a solid theoretical background and explanation. So as not to obscure the results by inclusion of patients with symptoms that are mainly subjective and difficult to quantify, we decided to test this new treatment modality in a difficult homogeneous group with objectively demonstrable detrusor instability and long-standing urge incontinence refractory to drug treatment. Of the patients who failed the percutaneous test stimulation 4 have undergone augmentation ileocystoplasty and most of the remainder are taking part in clinical trials with new drugs.

Combined with the low complication rate, the $83 \%$ success rate achieved in the implantation patients is promising $(61 \%$ with greater than a $90 \%$ and $22 \%$ with a 50 to $90 \%$ decrease in pad use and/or incontinence episodes). This effect appears to be durable as evidenced by the late results in the patients followed for longer than 2 years.

A neurophysiological explanation for the effectiveness of this treatment modality in detrusor instability is based on animal experiments and electrophysiological studies in humans. Spinal inhibitory systems capable of interrupting a detrusor contraction can be activated by electrical stimulation of afferent anorectal branches of the pelvic nerve, afferent sensory fibers in the pudendal nerve and muscle afferents from the limbs. ${ }^{5-7}$ Afferents from the pelvic floor muscles are without an inhibitory effect on the bladder, at least in the cat. ${ }^{14}$ An important argument in favor of the effectiveness of neuromodulation in humans is the objectively demonstrable urodynamic improvement, mainly because such effects are not noted in drug trials.

Although theoretically there are good explanations for its effectiveness, several points still need further clarification before neuromodulation can achieve the status of a firmly established treatment modality. For instance, in some patients it is not beyond doubt that the beneficial results are due to the treatment. One of the patients with long-term followup had not used the stimulator for 12 months and has not had relapse since that time. Another patient has not used the stimulator for 15 months but she had a more peculiar course. After initial complete success, leakage recurred after 6 months. The symptoms did not improve after increasing the amplitude of stimulation. One month later she decided to switch the stimulator off and surprisingly has remained completely dry since that time. Are the results as described in these 2 patients due to neuromodulation or do they represent variants of the natural history of the disease? Why do not all patients with urge incontinence due to an unstable bladder who underwent test stimulation react favorably, particularly if no neurological deficits have been found?

A further finding of interest is the discrepancy between the symptomatic improvement and the urodynamic findings. The symptomatic results are much better than one would expect on the basis of the urodynamic data. Standard urodynamic studies may possibly be too provocative. Ambulatory monitoring of detrusor pressures may be more informative and show better correlations. Proved effectiveness in other patients, for example those with detrusor instability due to neurogenic causes, would give this treatment modality a

TABLE 4. Effects of neuromodulation on urodynamic variables for the comparison of baseline and 6-month followup data in 18 patients studied in the standing position

\begin{tabular}{|c|c|c|c|c|}
\hline & \multicolumn{2}{|c|}{ Mean \pm SEM } & \multirow{2}{*}{ Mean Change } & \multirow{2}{*}{$\mathrm{p}$ Value } \\
\hline & Baseline Value & Followup (stimulation on) & & \\
\hline Bladder capacity at strong desire (ml.) & $318 \pm 44$ & $402 \pm 39$ & +84 & Not significant \\
\hline Bladder vol. at normal desire (ml.) & $204 \pm 34$ & $318 \pm 38$ & +114 & 0.001 \\
\hline \multicolumn{5}{|l|}{ First unstable contraction: } \\
\hline At vol. (ml.) & $253 \pm 47$ & - & - & - \\
\hline At vol. $(\mathrm{ml} .)^{*}$ & $206 \pm 40$ & $258 \pm 36$ & -52 & Not signifieant \\
\hline Detrusor pressure $(\mathrm{cm}$. water) & $27 \pm 5$ & $22 \pm 7$ & -5 & Not significant \\
\hline \multicolumn{5}{|l|}{ Maximum unstable contraction: } \\
\hline At vol. $(\mathrm{ml} .)^{*}$ & $251 \pm 40$ & $286 \pm 41$ & -35 & Not signifieant \\
\hline Detrusor pressure $(\mathrm{cm}$. water) & $40 \pm 7$ & $30=9$ & 10 & 0.03 \\
\hline Post-void residual (ml.) & $87=27$ & $68 \pm 24$ & -19 & Not significant \\
\hline
\end{tabular}



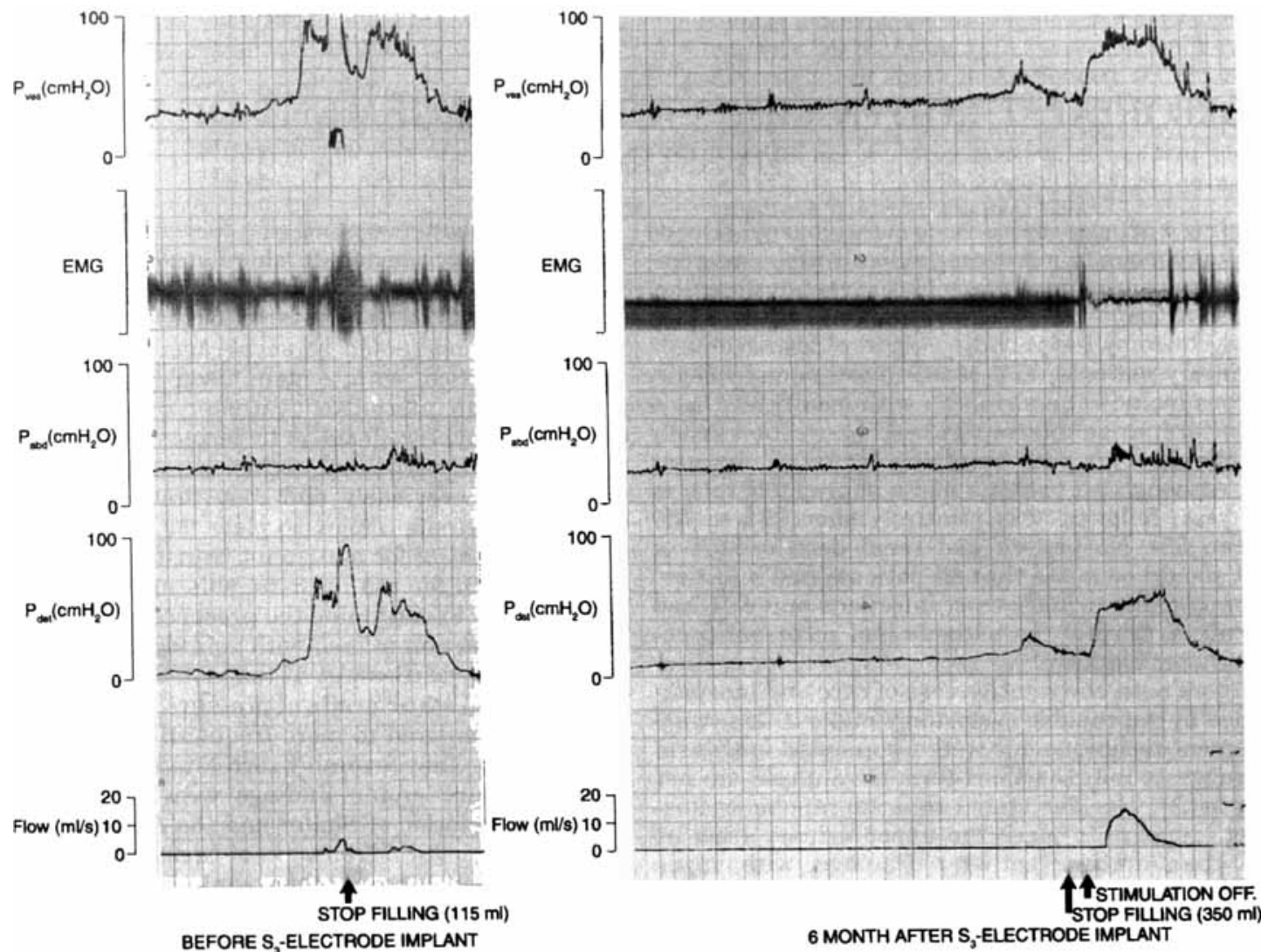

FIG. 3. Urodynamic studies in 45-year-old woman in standing position. Recording before implantation shows detrusor instability (maximum detrusor pressure $94 \mathrm{~cm}$. water) and involuntary leakage of urine at filled bladder volume of approximately $100 \mathrm{ml}$. Recording in same patient 6 months after implantation clearly shows that electrical stimulation is on during filling phase. No incontinence is noted. Clinically, patient is completely dry despite demonstrable unstable contraction (maximum detrusor pressure $24 \mathrm{~cm}$. water) at filled volume of more than $300 \mathrm{ml}$. during this urodynamic study. Pues, intravesical pressure. Pabd, abdominal pressure. Pdet, detrusor pressure. Flow, flow rate. EMG, electromyography.

more solid basis. A study in select multiple sclerosis patients has been initiated at our institution.

\section{CONCLUSIONS}

Neuromodulation is an effective treatment modality in patients with idiopathic detrusor instability and urge incontinence. This technology is a valuable addition to our treatment options in these difficult patients when conservative measures fail. The fact that no irreversible changes to the bladder or nerves occur is an advantage of this treatment option over alternatives, such as bladder augmentation. Before general acceptance of this technology, longer followup in patients treated to date is needed. Studies must be done comparing groups of patients randomly assigned to undergo implantation or no treatment to assess possible spontaneous improvements more accurately, as well as studies in patients with neurogenic voiding dysfunction, such as those with multiple sclerosis.

\section{REFERENCES}

1. Clinical Practice Guideline: Urinary Incontinence in Adults. Rockville, Maryland: U.S. Department of Health and Human Services, pp. 38-43, March 1992.

2. Zeegers, A. G. M., Kieswetter, H., Kramer, A. E. J. L. and Jonas, U.: Conservative therapy of frequency, urgency and urge incontinence: a double-blind clinical trial of flavoxate hydrochloride, oxybutinine chloride, emepronium bromide and placebo. World J. Urol., 5: 57, 1987.

3. Tapp, A., Fall, M., Norgaard, J., Massey, A., Choa, R., Carr, T., Korhonen, M. and Abrams, P.: Terodiline: a dose titrated, multicenter study of the treatment of idiopathic detrusor in- stability in women. J. Urol., 142: 1027, 1989.

4. Mundy, A. R.: The unstable bladder. Urol. Clin. N. Amer., 12: 317, 1985.

5. Fall, M. and Lindström, S.: Electrical stimulation. A physiologic approach to the treatment of urinary incontinence. Urol. Clin. N. Amer., 18: 393, 1991.

6. Vodušek, D. B., Light, J. K. and Libby, J. M.: Detrusor inhibition induced by stimulation of pudendal nerve afferents. Neurourol. Urodynam., 5: 381, 1986.

7. Vodušsek, D. B., Plevnik, S., Vrtacnik, P. and Janež, J.: Detrusor inhibition on selective pudendal nerve stimulation in the perineum. Neurourol. Urodynam., 6: 389, 1988.

8. Schmidt, R. A., Senn, E. and Tanagho, E. A.: Functional evaluation of sacral nerve root integrity. Report of a technique. Urology, 35: 388, 1990.

9. Abrams, P. H., Blaivas, J. G., Stanton, S. L. and Andersen, J. T. Appendix: Standardizetion of terminology of lower urinary tract function. In: Clinical Neurourology, 2nd ed. Edited by R. J. Krane and M. B. Siroky. Boston: Little, Brown \& Co., pp 649-669, 1991.

10. Siegel, S. W.: Management of voiding dysfunction with an implantable neuroprosthesis. Urol. Clin. N. Amer., 19: 163, 1992.

11. Schmidt, R. A.: Applications of neurostimulation in urology. Neurourol. Urodynam., 7: 585, 1988.

12. Dijkema, H. E., Weil, E. H., Mijs, P. T. and Janknegt, R. A. Neuromodulation of sacral nerves for incontinence and voiding dysfunctions. Clinical results and complications. Eur. Urol., 24: 72, 1993

13. Hohenfellner, M., Thüroff, J. W., Schmidt, R. A. and Tanagho E. A.: Neurochirurgische Eingriffe zur Behandlung von Miktionsstörungen. Akt. Urol., 23: 47, 1992.

14. Lindström, S. and Sudsuang, R.: Functionally specific bladder reflexes from pelvic and pudendal nerve branches; an experimental study in the cat. Neurourol. Urodynam., 8: 392, 1989. 